\title{
Mysterium tremendum: el sacrificio humano como motivo literario en la narrativa latinoamericana contemporánea
}

Edyta Andzel-O'Shanahan

Investigadora independiente

Ninguna otra faceta de la cultura mesoamericana pareció despertar en los españoles tanto terror y repugnancia como el sacrificio humano, a pesar de que fueron relativamente pocos los testigos presenciales de aquel ritual. ${ }^{1}$ Díaz del Castillo lo califica de "grandísima crueldad" y recuerda con horror haber visto "sacrificados [...] indios [...] abiertos por los pechos y cortados los brazos y los muslos y las paredes de las casas llenas de sangre". ${ }^{3}$ Durán escribe sobre "mil géneros de crueldades y muertes" y tilda el oficio de los sacerdotes principales y los chachalmeca de "sangrienta dignidad endemoniada". ${ }^{4}$ Sahagún por su parte se horroriza ante la relación de los sacrificios de niños:

No creo que haya corazon tan duro, que oyendo una crueldad tan inhumana, y mas que bestial y endiablada [...], no se enternezca y mueva á lágrimas, horror y espanto; y ciertamente es cosa lamentable y horrible, ver que nuestra humana naturaleza haya venido á tanta bajeza de

\footnotetext{
1 GonzÁLes Torres 1994: 77.

2 Díaz del Castillo 1998: 85.

3 Díaz del Castillo 1998: 84.

${ }^{4}$ Durán 2005b: 92
} 
degradacion y oprobio, que los padres por sugestion del demonio, maten y coman á sus hijos. ${ }^{5}$

El sacrificio humano y la antropofagia ritual en los relatos de los cronistas e historiadores españoles sirven de la definitiva línea divisoria entre la civilización europea y el salvajismo del Nuevo Mundo. Son indispensables para la definición del Otro, humano pero moralmente inferior, y validan la dicotomía civilización/barbarie en la que se basa el mito de la conquista. Kimberle S. López en su excelente trabajo investigativo sobre la novela latinoamericana de la conquista pone de relieve la importancia del constructo literario del Otro, acuñando el término de la "ansiedad de identificación" o el miedo a la pérdida de la identidad del sujeto europeo y las fronteras del ego durante el proceso del contacto intercultural. ${ }^{6}$ Partiendo del concepto del deseo colonial caracterizado por "los impulsos simultáneos de atracción y repugnancia experimentados por el sujeto colonizador hacia el colonizado Otro", ${ }^{7}$ López subraya la compleja ambigüedad de la reacción psicológica del colonizador europeo a los sacrificios humanos y el canibalismo ritual. La repugnancia que resulta en la violencia contra el sujeto subalterno "puede ser vista como un mecanismo de defensa psicológica causada por el miedo al Otro interno", ${ }^{8}$ entendido como los miedos y los impulsos inconscientes universales. Para los europeos, el enfrentamiento con las más inquietantes facetas del Otro era simultáneamente un enfrentamiento con el $\mathrm{id}$, el "yo" primitivo y no civilizado pero fascinante. La violencia y el desprecio extremo de las difierencias religiosas y culturales pueden surgir precisamente como consecuencia del miedo a la identificación con el colonizado. ${ }^{9}$

Numerosas investigaciones sobre el tema del sacrificio humano en Mesoamérica, incluso las más recientes, demuestran que "la ideología que los investigadores expresan está íntimamente ligada con su concepto de la religión"10 o sea que escasean las aproximaciones imparciales e impasibles a este tema. El propósito de este trabajo es tratar de situar el sacrificio humano dentro de la cosmovisión mexica y entender su significado en el contexto religioso y sociopolítico. Posteriormente se analizarán ejemplos del empleo del sacrificio humano como motivo literario en la narrativa latinoamericana de los siglos XX y XXI. Se evaluará el grado de su distanciamiento del contexto cultural original y de ilustrará su reinterpretación y resemantización. Dado que existen estudios detallados sobre la novela latinoamericana de la conquista o las nuevas crónicas

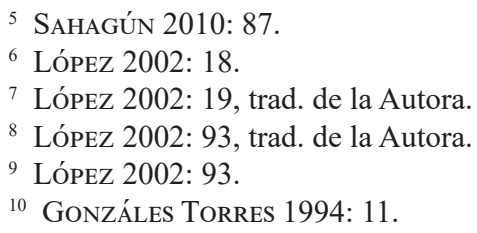


de Indias (con las publicaciones de Kimberle S. López y de Carolina Pizarro Cortés entre las más destacadas), se excluye del presente análisis el mencionado corpus narrativo. La selección de los ejemplos para el presente artículo ambiciona ejemplificar la variedad de los empleos de un motivo derivado de la tradición cultural prehispánica en diferentes contextos ideológicos y estéticos, además de diferentes subgéneros narrativos.

Como sacrificio humano entenderemos "una violencia sancionada que se lleva a cabo dentro del campo de lo sagrado, [...] aceptada [...] por la comunidad". ${ }^{11}$ La finalidad del sacrificio en el mundo mexica, en rasgos generales, era el mantenimiento del equilibrio de la energía entre el mundo sobrenatural y el natural, puesto que ambos eran interdependientes y se complementaban mutuamente. Gonzáles Torres define esta energía como "un flujo, una corriente, un poder que existe en todo el mundo". ${ }^{12}$ Dicha energía se la entregaba a las divinidades por medio de la sangre humana, "comida sabrosa y caliente de los dioses". ${ }^{13}$ No extraña entonces el empleo del sacrificio como método del mantenimiento o de la restauración del equilibrio cósmico en los tiempos percibidos como inestabilidad, por ejemplo durante las sequías o el equinoccio. De este modo, los seres humanos participaban en la realidad cosmo-mágica por medio de la coordinación de la orden social humana con la divina sociedad de los dioses. ${ }^{14}$ Dos de los antiguos mitos mexicas en particular ponen de relieve esta correlación entre las fuerzas sobrenaturales y el mundo humano. Uno de ellos se refiere a la creación de la tierra y del cielo del cuerpo de la divinidad Tlaltecuhtli, quien demanda la alimentación con sangre humana a cambio de su sacrificio. El otro mito abarca la narración sobre el sacrificio supremo de Nanahuatzin y Tecciztecatl, cuyas muertes posibilitan la creación del Quinto Sol, propicio para la existencia de los seres humanos.

Partiendo de la premisa de que el mexica era un hombre sumamente religioso, no es difícil entender como prácticamente todo el cosmos, desde el movimiento de los cuerpos celestes hasta la fundación de la urbe principal mediante la intervención divina, constituía para él una hierofanía o sea una manifestación de lo sagrado. ${ }^{15}$ La sustentación de la comunicación con el mundo sobrenatural era una responsabilidad grave, debida a los dioses a cambio de su propio sacrificio. La inmolación de las víctimas, más allá de propiciar beneficios para la comunidad, garantizaba la continuación del flujo de la energía y la renovación de la vida. Tanto el sacrificio mismo como las ceremonias que lo acompañaban se

\footnotetext{
11 GonZÁles TORRES 1994: 28.

12 GonZÁles Torres 1994: 29.

13 Durán 2005b: 94.

14 Carrasco 1999: 29.

15 Eliade 1987: 11.
} 
regían en la mayoría de los casos por el calendario ritual. Según Eliade, los ritos sagrados no sólo conmemoran y dramatizan el tiempo mítico, illud tempus, sino más bien lo reactualizan. ${ }^{16}$ Durante la realización del rito expiatorio, por un instante el hombre se volvía contemporáneo con los dioses y con el tiempo primordial, ${ }^{17}$ mientras que la víctima se deificaba, se convertía en in ixiptla in teteo. ${ }^{18}$

Sin embargo, cabe también mencionar que el sacrificio humano no desempeñaba solamente un papel religioso: poseía además un valor ideológico en el ámbito político. Recordemos que el dios del estado azteca era Huitzilopochtli, el dios guerrero. "En su templo y en su honor se llevaban a cabo todos los sacrificios masivos que formaban parte del pacto establecido entre el pueblo mexica y el dios que los había llevado a la cúspide del poder, y de su renovación". ${ }^{19}$ Entre otros ritos, la recreación del mito de la victoria de Huitzilopochtli sobre su hermana Coyolxauhqui y los Centzonhuitznahua rememoraba el pasado belicoso de los mexica y aseguraba su triunfo sobre sus enemigos. Con el tiempo "el rito sacrificial se volvió una demonstración de poder del Estado y el aspecto religioso pasó a un segundo plano. Se convirtió en una excusa para exhibir el poderío mexica y por ello adquirió mayor espectacularidad". ${ }^{20}$

Casi quinientos años después de la conquista de México el sacrificio humano no deja de inspirar la imaginación artística de los escritores latinoamericanos. El valor semántico del sacrificio, sin embargo, se va cambiando y alejando del original. A continuación se analizarán cuatro ejemplos de la narrativa latinoamericana contemporánea que demuestran varios patrones del diálogo con la modalidad mítico-ritual y de la interrogación sobre el sacrificio humano como un símbolo universal. Además de la desacralización, la universalización simbólica del rito mexica en cierto sentido conlleva el desvanecimiento de la dicotomía yo (europeo o europeizado)/el Otro (americano). La identificación con el Otro sucede, sin embargo, más frecuentemente en el plano pasivo, en su condición de la víctima más bien que del perpetrador.

El sacrificio es el motivo simbólico principal de la novela de Carlos Fuentes Cambio de Piel (1967), cuyos protagonistas emprenden un viaje desde la Ciudad de México hasta la costa veracruzana, o sea en trayectoria inversa de la expedición de Cortés hacia Tenochtitlán. ${ }^{21}$ El sacrificio humano efectuado por los mexicas se inscribe dentro de un círculo eterno de la repetición de la violencia, tanto al nivel histórico como en su dimensión universal humana

\footnotetext{
16 Eliade 1987: 86.

17 Eliade 1987: 87.

${ }_{18}$ Carrasco 1999: 83.

19 GonzÁles Torres 1994: 143.

20 GonZÁles Torres 1994: 242.

21 SÁENZ NeGrete 2007: 654.
} 
atávica. ${ }^{22} \mathrm{El}$ mítico eterno retorno queda mejor ilustrado por el simbolismo de dos antiguos centros ceremoniales, Xochicalco y Cholula. En Xochicalco, el bajorrelieve de Quetzalcóatl, "talud que es una sola e interminable serpiente trenzada sobre sí misma", ${ }^{23}$ recuerda a los viajeros que en realidad todo principio es un fin, la muerte es la creación de una vida nueva y "el apocalipsis es la otra cara de la creación". ${ }^{24}$ Cholula, por otro lado, es un sitio antiguo sobre cuyas ruinas a un modo de un palimpsesto "se levantarán cuatrocientas iglesias: sobre los cimientos de los cúes arrasados, sobre las plataformas de las pirámides negras y frías en la aurora humeante del nuevo día". ${ }^{25}$ Dos pilas bautismales en la capilla de la iglesia no son "sino urnas de piedras indígenas, [...] antiguos depósitos de los corazones humanos arrancados por el pedernal en los sacrificios de Cholula" ${ }^{26}$ Aunque en lugar de corazones humanos ahora se ofrezcan inciensos y candelas, en la novela la pirámide, al derrumbarse, reclamará otra vez dos víctimas humanas. Franz, un arquitecto nazi, responsable de la construcción del horno crematorio para el gueto de Theresienstadt y Elizabeth, la esposa judía norteamericana de Javier, mueren bajo los escombros de la pirámide.

En Cambio de Piel los sacrificios humanos prehispánicos forman parte del círculo de violencia propiamente humana y universal, donde "nada termina. Nada se resuelve. Y todo debe ser vivido, revivido, una y otra vez". ${ }^{27} \mathrm{La}$ violencia repetida a través de siglos sigue exigiendo víctimas. El discurso de la novela pone un énfasis particular en la persecución de los judíos, vistos como los chivos expiatorios de la historia. Entre los acontecimientos históricos mencionados en la novela se encuentran las masacres de los judíos acusados de envenenar pozos y de causar la epidemia en la Europa medieval (masacre de Estrasburgo en 1349 $)^{28}$, y el holocausto en los campos de concentración. La visión de la historia que nos ofrece Fuentes resulta sumamente pesimista: del círculo de la violencia no hay salida ni posibilidad de redención. Cada intento de rebeldía contra el mal inherente en la naturaleza humana está destinado al fracaso, puesto que "la rebelión triunfante se vuelve también institución y ley de una nueva opresión". ${ }^{29}$ El Renacimiento europeo con su humanismo no logrará evitar "los hornos de Auschwitz" ni "el llano arrasado de Hiroshima". ${ }^{30}$ En palabras de Fuentes, "el mal verdadero sólo nos muestra que el mal también es humano",

\footnotetext{
22 SÁENZ Negrete 2007: 653.

23 Fuentes 1984: 40.

${ }^{24}$ Fuentes 1984: 462.

${ }^{25}$ Fuentes 1984: 15.

${ }^{26}$ Fuentes 1984: 18.

27 Fuentes 1984: 484.

${ }^{28}$ Véase: FuENTES 1984: 268.

${ }^{29}$ Fuentes 1984: 450.

${ }^{30}$ Fuentes 1984: 270.
} 
propio de "hombre y sus Posibilidades. Las Más Terribles". ${ }^{31}$ El cambio de piel en el título de la novela entonces puede referirse a varios aspectos y manifestaciones del mismo instinto universal. Las culebras se deshacen de su piel antigua cuando ya no la aguantan, solo para vestirse de una piel nueva que no será nada más que la repetición modificada de la previa. ${ }^{32}$ Asimismo el Narrador misterioso se revela a principios de la última y la más compleja parte de la novela como Xipe Totec, "nuestro señor el desollado". La piel de la víctima sacrificada cada año al honor de aquel dios mexica servía de vestimenta morbosa portada por los guerreros y los personificadores del dios durante 20 días hasta que la piel se pudriera casi por completo. ${ }^{33}$ Sin embargo, Xipe era también el dios de la fertilidad y de la renovación, sobre todo en el contexto de la agricultura. La putrefacción de la piel de la víctima desollada pregonaba el comienzo del nuevo ciclo y la regeneración de la vida, sometida constantemente a las leyes naturales de muerte y renacimiento.

En el relato La noche boca arriba (1956) de Julio Cortázar existen dos planos temporales discursivos paralelos: el del siglo XX, que abarca la historia de un motociclista accidentado y llevado al hospital para recibir tratamiento, y el del mundo mexicano precortesiano, posiblemente durante un episodio de la guerra florida. Las guerras floridas, una estrategia bélico-ritual de los antiguos mexicas que servía para captar presos destinados al sacrificio, constituyen un hecho histórico bastante bien documentado. Diego Durán sitúa los comienzos de las guerras floridas durante el gobierno de Motecuhzoma Ilhuicamina, poco antes del periodo de las grandes sequías (1454-1457). ${ }^{34} \mathrm{El}$ propósito de esta "feria militar", ${ }^{35}$ además de proporcionar oportunidades para el ejercicio bélico, era conseguir presos de Tlaxcala, Huexotzingo y Cholula para sacrificarlos en el altar del dios Huitzilopochtli. Como presuntamente aconsejó Tlacaélel, "a de ser esta guerra de tal suerte, que no pretendamos destruillos, sino que siempre que esté en pié, para que cada y quando que queramos nuestro dios quiera comer y olgarse acudamos allí como quien va al mercado á mercar de comer" ${ }^{36}$ El destino de los varones captados durante la guerra florida estaba sellado: su único propósito era sustentar el orden divino con su sangre, asegurando la victoria del sol sobre la oscuridad nocturna.

En el relato de Cortázar, la transición del plano temporal moderno al prehispánico a principios queda explicada por una pesadilla. El motociclista herido

\footnotetext{
31 Fuentes 1984: 438, 439.

32 Fuentes 1984: 447.

33 Miller, Taube 1997: 188.

${ }^{34}$ Durán 2005a: 239, 240.

35 Durán 2005a: 240.

36 Durán 2005a: 239.
} 
sueña, bajo los efectos de la fiebre y de los medicamentos, con trasladarse al tiempo histórico-mítico en el que le toca huir de los mexicas, sólo para despertarse en el ámbito seguro y acogedor del hospital. Para distinguir entre los dos planos temporales y espaciales, el protagonista se guía por el sentido de olfato: mientras la selva "huele a guerra", el hospital huele al caldo de oro: puerro, apio, perejil. ${ }^{37}$ Sin embargo, las oscilaciones entre los dos tiempos y espacios se intensifican y la línea divisoria entre ellos se va borrando hasta tal punto que el lector con dificultad llega a distinguirlos. Al final al lector no le queda otro remedio sino aceptar que el motociclista es de verdad un preso de guerra, una víctima a punto de estar sacrificada que está soñando con la otra realidad moderna. Al final del relato aumenta también el sentido de terror e impotencia ante el inevitable final que le espera al protagonista tendido boca arriba en el quirófano y rodeado por los médicos y los enfermeros. El protagonista-guerrero muere simultáneamente en el tiempo y espacio paralelos, sacrificado por los acólitos de los sacerdotes aztecas.

Los dos planos temporales llegan a superponerse, a fundirse y por extensión, a equipararse. Numerosos paralelismos en el relato (hospital/teocalli, médico/sacerdote, calle bordeada de árboles/calzada en la selva, bisturí/puñal, etc.) conducen al lector a yuxtaponer mentalmente mediante la simetría los dos tiempos y espacios. Con la inversión de los planos termporales y espaciales en el desenlace final se desenmascara la ilusoria naturaleza del plano "real" - lo onírico acaba por volverse verídico y la seguridad aparente del siglo XX, con su progreso y sus avances en el campo de medicina, resulta ser "la mentira infinita". ${ }^{38}$ El protagonista no logra huir de su destino, despertarse protegido y amparado en el mundo moderno. El ser humano resulta igual de impotente ante la muerte en el siglo XX que en el XV y el sacrificio humano llega a convertirse en un símbolo de dicha impotencia.

En el relato fantástico Huitzilopoxtli. Leyenda mexicana (1914), Rubén Darío también recurre al motivo del sacrificio humano. A medida que los tres protagonistas: el narrador-periodista, un médico estadounidense John Perhaps y un viejo fraile vasco Padre Reguera avanzan en su viaje al territorio controlado por el ejército de Pancho Villa, va cambiando notablemente el ambiente del cuento. Los protagonistas dejan atrás su coche y siguen penetrando en la selva a caballo y mulas a la caída de la noche. Las tinieblas, los aullidos de los coyotes y una inexplicable luz dorada subrayan el ambiente de misterio y temor. Los protagonistas se sumergen en el bosque, un símbolo de lo arcaico, lo alejado de la civilización, lo instintivo y lo mágico. Adicionalmente, al ambiente del temor inconsciente se suma la sugerencia de los efectos de los estupefacientes:

37 CoRtázar 1989: 134.

38 CORTÁZAR 1989: 139. 
el alcohol y la marihuana. De este modo, cuando el narrador presencia un ritual del sacrificio humano, cuya víctima es John Perhaps, la interpretación de aquel acontecimiento puede ser ambigua, atribuida a una alucinación que crea una realidad subjetiva. Un lector atento notará una incongruencia entre el texto del relato y el paratexto: el ídolo de piedra observado por el narrador instantemente trae a la mente la estatua de Teoyaomiqui-Coatlicue, identificada por las cabezas de serpientes y el collar de las manos cortadas. Sin embargo, el título del cuento se refiere a otra divinidad mexica, el dios de la guerra, el hijo de Coatlicue. Una posible pauta interpretativa permite entender el sacrificio del señor Perhaps no como un ritual particular en el honor de una divinidad concreta sino como una amenaza simbólica del conjunto de creencias antiguas al progreso civilizador, al empirismo decimonónico, a lo moderno y a lo razonable. Como explica Padre Reguera, "en México, sobre todo, se vive en un suelo que está repleto de misterio. Todos esos indios que hay no respiran otra cosa. Y el destino de la nación mexicana está todavía en poder de las primitivas divinidades de los aborígenes". ${ }^{39}$ Tanto el ambiente misterioso de la segunda parte del cuento como las palabras del Padre Reguera sugieren la existencia de una realidad que se opone a los métodos científicos modernos, a los intentos de cristianización y a la cruda realidad mexicana durante la revolución.

Las creencias religiosas prehispánicas vuelven a irrumpir en la cotidianidad mexicana en la novela Toda la sangre (2013) de Bernardo Esquinca, que se inscribe dentro del subgénero neopolicial, incluyendo al mismo tiempo elementos propios de la narrativa fantástica y de terror. En esta novela, el sacrificio humano desempeña un papel clave en el desarrollo de la trama que abarca la investigación del caso del asesino ritual. Un homicida en serie está replicando el rito del sacrificio humano, dejando una huella de corazones humanos, cráneos desollados y sangre derramada. La intriga se desarrolla en la ciudad de México, donde reina la desigualdad social, la corrupción al nivel político y la desintegración del sistema de valores morales. A la trama de la novela se suman referencias históricas, notablemente las relacionadas con el desterramiento del monolito de Coatlicue por Alejandro de Humboldt y el hallazgo de la estatua de Tlaltecuhtli por los arqueólogos del Instituto Nacional de Antropología e Historia. La narración, aunque en tercera persona singular, engloba varias perspectivas psicológicas, con el más importante aporte de fragmentos del cuaderno del asesino. Tras varios intentos de desmitificación del significado de los crímenes cometidos por el asesino, atribuidos a los delirios de grandeza, la esquizofrenia o la psicopatía,${ }^{40}$ el homicida emerge como un personaje mucho más complejo

39 DARÍo 2003: 2.

40 ESQUINCA 2013: 277. 
que "sólo un chiflado más". ${ }^{41}$ Su objetivo es el de "instaurar un nuevo orden" y "el regreso del mundo prehispánico por encima del moderno". ${ }^{42}$ Para conseguirlo, el asesino "se está valiendo del poder mágico de la sangre". ${ }^{43}$ No se trata entonces de un psicópata quien sólo está satisfaciendo su instinto asesino; Yólotl se cree más bien una especie de encarnación de Xipe Totec con la misión de la reivindicación del esplendoroso pasado mexica. Su cuaderno ofrece pistas para la comprensión de su psique: "Los dioses reclaman sangre. La necesitan para regresar e instaurar el nuevo orden. Y yo soy su instrumento. Xipe Totec decidió encarnar en mí y comandar los sacrificios requeridos. Soy El Elegido". ${ }^{44}$

Aunque a lo largo del discurso predomina el ambiente de misterio y terror propio del subgénero neopolicial y las descripciones morbosas de los restos humanos abundan en el texto, se nota efectivamente un intento de penetrar en el significado profundo de los sacrificios mexicas. La arqueóloga Elisa Matos explica:

Los sacrificios aztecas tenían una razón de ser profunda, estaban relacionados con la continuidad del cosmos. La sangre derramada era el alimento que el Sol necesitaba para vencer todas las noches a las estrellas y resurgir victorioso por las mañanas. Lo que reflejaban era una concepción compleja del mundo, no una tendencia asesina. ${ }^{45}$

El personaje de González Rodríguez complementa la explicación de Elisa: "Para ellos la sangre era el corazón líquido. En los sacrificios humanos extraían aquel órgano de las víctimas para restaurar el orden cósmico" y después, citando a J.M.G. Le Clèzio: "La sangre es el símbolo de esta ebriedad mística, que permite el reencuentro entre los hombres y sus dioses". ${ }^{46}$

Yólotl, el asesino ritual, no es el único personaje de la novela que se interesa por despertar a los dioses antiguos: lo es también El Brujo, el cómplice del homicida, protegido por un alto cargo de la policía. El Brujo se apodera del Códice Borgia, el libro mágico trasladado a México desde la Biblioteca Vaticana. El códice le permite "transgredir los límites entre la vida y la muerte" y convertir al asesino ritual en el "Caudillo de la Guerra". ${ }^{47}$ De hecho, Yolótl reaparece

\footnotetext{
${ }^{41}$ ESQUINCA 2013: 110.

42 ESQUINCA 2013: 110.

43 ESQUINCA 2013: 110.

44 EsQUinca 2013: 239 .

45 EsQuinca 2013: 80.

46 EsQuinca 2013: 109.

${ }^{47}$ Esquinca 2013: 333.
} 
entre los danzantes concheros cerca de la Catedral "cierto tiempo después" su muerte. Su misión continúa.

\section{CONCLusiones}

El sacrificio humano era una práctica extendida prácticamente por todo el mundo a través de milenios de la historia de la humanidad. Sin embargo, "fueron solamente los mexicas y algunos otros pueblos mesoamericanos, como los tlaxcaltecas y los huexotzincas, los que sacrificaron hombres en cantidades tan grandes y con tanta frecuencia". ${ }^{49} \mathrm{El}$ análisis lingüístico de la palabra sacrificio proporciona pistas claves para el entendimiento de su significado: la palabra proviene del latín sacrificium, "voz que a su vez está compuesta de las raíces sacer, «sagrado», y facere, «hacer»; esto es, «convertir algo en sagrado»". ${ }^{50}$ De hecho, el corazón y la sangre de la víctima se convertía en el sustento sagrado de los dioses y aseguraba el flujo de la energía entre el mundo humano y el divino. En mayoría de los casos, los ritos relacionados con el sacrificio pretendían representar y reactualizar un mito. Los ritos se regían por algunas reglas estrictas, como la ubicación temporal (acorde con el calendario ritual) y espacial, la selección de la víctima que debía cumplir con requisitos específicos, el atuendo tanto de los sacerdotes como de la víctima, el método de la inmolación o de tortura previa a la occisión (cardioectomia, degollamiento, flechamiento) $\mathrm{y}$ los ritos posteriores al sacrificio (p.ej. desollamiento, antropofagia). En la historia mexica se nota un incremento del número de las víctimas (p.ej. las mencionadas guerras floridas o la reconsagración del Templo Mayor en 1487) y la intensificación del significado del sacrificio humano como herramienta del poder en las manos de la clase especializada urbana dentro del Estado centralizado. Como observa González Torres, "el sacrificio se convierte, con su función reguladora y controladora de la violencia, en un medio de manipulación y de obtención de poder político a través del manejo de la ideología y de las fuerzas sobrenaturales". ${ }^{51}$

Sin lugar a dudas, el sacrificio humano era un ritual aterrador y tremendo, una formidable celebración del misterio sagrado (mysterium tremendum).$^{52} \mathrm{Al}$ gunos datos históricos permiten observar que el rito de inmolación de víctimas inocentes llenaba de horror no sólo a los conquistadores españoles sino también

\footnotetext{
48 ESQUINCA 2013: 338.

49 GonZÁlez Torres 1994: 303.

50 GONZÁlez TORRES 1994: 25.

51 GonZÁlez TORRES 1994: 35-36.

52 Eliade 1987: 9.
} 
a los mexicas. No era un ritual fácil ni placentero para los sacerdotes. González Torres por ejemplo nota que los sacrificadores debían pintarse el cuerpo con un tizne llamado teotlaqualli cuyo propósito era "infundirles valor para sacrificar a los hombres". ${ }^{3}$ "A los sacerdotes que se rehusaban a matar niños los 1lamaban mocauhque, «dejados»" ${ }^{54}$, indignos de desempeñar oficios públicos. Las tradicionales fuentes históricas mencionan también el personaje medio mítico del sacerdote supremo de los antiguos Toltecas, Ce-Acatl Topiltzin Quetzalcoátl, quien se oponía a los sacrificios humanos y a consecuencia de un cisma religioso se vio obligado a huir de Tula. ${ }^{55}$ La inmolación de las víctimas era una tarea horrenda pero últimamente vista como indispensable en el mantenimiento del equilibrio cósmico, una responsabilidad tremenda ante las fuerzas superiores al ser humano.

El aspecto morboso y aterrador del sacrificio se presenta sin duda en todos los ejemplos de la narrativa latinoamericana moderna seleccionados para este artículo. Sin embargo, las obras analizadas se sirven también de algunas connotaciones de este rito alejadas considerablemente de su significado religioso y mítico. De este modo, el motivo de sacrificio humano adquiere un valor simbólico resemantizado y desacralizado, con el fin de ilustrar diferentes conceptos universales o político-sociales. Las novelas y los relatos analizados emplean el motivo del sacrificio con valores connotativos de la impotencia ante la muerte o de la violencia inherente al ser humano. En mayoría de los ejemplos, desaparece casi por completo el significado religioso original del rito por medio del cual el ser humano se comunicaba con lo divino y cumplía un papel activo e importante en perpetuar la vida. La repulsión ante el ritual sangriento en la narrativa contemporánea, aunque matizada, coincide con la de los conquistadores españoles en el siglo del incipiente humanismo europeo. No es un hecho extraño, dado el común marco ideológico eurocéntrico tanto de los cronistas españoles como de los escritores mencionados. Sin embargo, la ansiedad de identificación con el Otro ya no parece enraizada en el miedo a la pérdida de la identidad europea, sino adquiere dimensiones universales.

En la novela de Carlos Fuentes el sacrificio se equipara a la violencia histórica, especialmente la institucionalizada, repetida en varias formas a través de siglos. El sacrificio ritual precortesiano pierde el sentido religioso y forma parte del eterno círculo de violencia inherente en el ser humano.

Fueron hombres. ¿Dónde están? [...] El sol de agua inunda este mundo y estos hombres mueren ahogados. [...] ¿En qué nos distinguimos de ustedes? ¿Esperamos como ustedes los cataclismos, la ruptura del velo,

53 GonzÁlez Torres 1994: 191.

54 González Torres 1994: 191.

55 LeÓN-Portilla 1961: 37. 
la aparición de los monstruos de crepúsculo que habrán de devorarnos?

¿No están siempre entre nosotros? ${ }^{56}$

Ni siquiera el juicio de los culpables asegura la redención: no es más que "parte de la dialéctica del mito". ${ }^{7}$

El relato La noche boca arriba de Julio Cortázar reinterpreta el sacrificio humano en el contexto de terror existencial ante la inevitabilidad de la muerte. El escritor argentino recurre a los motivos histórico-míticos prehispánicos, en particular al rito de sacrificio, para ilustrar unas verdades filosóficas y psicológicas universales: la fragilidad de la vida humana, la impotencia ante la muerte, y la inevitabilidad del óbito. Rubén Darío se sirve del mismo motivo del sacrificio para ilustrar la existencia de una realidad irracional, subconsciente: el tema predilecto de los modernistas, tanto hispanoamericanos como europeos. Las facetas morbosas y horribles de la violencia ritual se presentan también en la novela de Bernardo Esquinca. No son, sin embargo, sólo noticias de primera plana de la nota roja: los crímenes del asesino forman parte de una misión de instauración de un nuevo orden basado en las creencias antiguas, en respuesta a la desintegración del sistema de valores en el México moderno, corrupto y enviciado. Aunque el escritor jalisciense se acerca más al significado original del rito, no logra evitar algunas simplificaciones. El personaje del asesino, Yólotl, por ejemplo, inevitablemente trae a la mente del lector lo primitivo y lo atávico por su aspecto y su potencia sexual.

Los ejemplos seleccionados para el artículo por supuesto no agotan, ni mucho menos, el corpus narrativo latinoamericano que incluye el sacrificio humano como motivo literario. Sin embargo, demuestran varias aproximaciones sumamente interesantes al diálogo con la historia y el mito. Un aspecto del sacrificio como motivo literario resulta indiscutible: el misterio tremendo sigue inspirando la imaginación.

\section{Bibliografía}

Carrasco 1999 - Davíd Carrasco, City of Sacrifice. The Aztec Empire and The Role of Violence In Civilization, Boston: Beacon Press 1999.

Cortázar 1989 - Julio Cortázar, Ceremonias, Barcelona: Seix Barral 1989. DARío 2003 - Rubén Darío, Huitzilopochtli. Leyenda mexicana, Biblioteca Virtual Universal, Editorial del Caldo 2003.

56 Fuentes 1984: 218.

57 FueNTES 1984: 239. 
DíAz del Castillo 1998 - Bernal Díaz del Castillo, Historia verdadera de la conquista de Nueva España. Barcelona: Plaza \& Janés 1998.

DuRÁn 2005a - Diego Durán, Historia de las Indias de Nueva España y islas de Tierra Firme, Tomo I, Alicante, Biblioteca Virtual Miguel de Cervantes 2005. Consultado en septiembre 2017 en http://www.cervantesvirtual.com/obra/historia-de-las-indias-de-nueva-espana-y-islasde-tierra-firme-tomo-i- $0 /$.

DurÁN 2005b - Diego Durán, Historia de las Indias de Nueva España y islas de Tierra Firme, Tomo II, Alicante, Biblioteca Virtual Miguel de Cervantes 2005. Consultado en septiembre 2017 en http://www.cervantesvirtual.com/obra/historia-de-las-indias-de-nueva-espana-y-islasde-tierra-firme-tomo-ii- $0 /$.

Eliade 1987 - Mircea Eliade, The Sacred \& The Profane. The Nature of Religion. San Diego: Harcourt Brace \& Company 1987.

EsQuinca 2013 - Bernardo Esquinca, Toda la sangre, Oaxaca: Almadía 2013.

FuEntes 1984 - Carlos Fuentes, Cambio de piel, Barcelona: Seix Barral 1984.

GonzÁlez Torres 1994 - Yolotl González Torres, El sacrificio humano entre los mexicas, México: Fondo de Cultura Económica 1994.

León-Portilla 1961 - Miguel León-Portilla, Los antiguos mexicanos a través de sus crónicas y cantares, México: Fundo de Cultura Económica 1961.

López 2002 - Kimberle S. López, Latin American Novels of the Conquest. Reinventing the New World. Columbia: University of Missouri Press, 2002.

Miller, Taube 1997 - Mary Miller, Karl Taube, An Illustrated Dictionary of The Gods and Symbols of Ancient Mexico and the Maya, London: Thames \& Hudson 1997.

Moreno 2015 - Fernando Moreno, Toda la sangre, de Bernardo Esquinca: los mitos en el neo-policial', en: Helena Usandizaga y Beatriz Ferrús (eds.) Fragmentos de un nuevo pasado. Bern: Peter Lang, 2015, pp. 263-278.

SÁEnZ Negrete 2007 - Inés Sáenz Negrete, "El círculo de violencia en Cambio de Piel de Carlos Fuentes y José Trigo de Fernando de Paso, en: Actas del XV Congreso de la Asociación Internacional de Hispanistas, vol. IV, 2007, México: Fondo de Cultura Económica, pp. 653659.

SAHAGún 2010 - Bernardo de Sahagún, Historia general de las cosas de Nueva España, vol. 1, New York: Cambridge University Press 2010. 


\section{Summary}

\section{Mysterium tremendum - human sacrifice as a literary motif in contempo- rary Latin-American prose fiction}

The aim of this article is twofold: firstly, it examines the meaning and the role of the frightening Aztec ritual of human sacrifice in its original religious and political context. Human sacrifice was an integral part of the Aztec world view. It facilitated the communication between the supernatural forces and the human world through the interchange of vital energy. Human sacrifice also had a political meaning, as over time it intensified and was transformed into a formidable display of state power. Secondly, the article investigates the use of human sacrifice as a literary motif in modern Latin-American prose fiction. The selected examples illustrate how the Aztec ritual has acquired different connotative values, distant from its original denotation. It has been transformed into a symbol of historical violence, existential fears and irrational reality.

Keywords: human sacrifice, violence, Xipe Totec, Huitzilopochtli, Aztec ritual

\section{Streszczenie}

\section{Mysterium tremendum - rytual składania ofiar z ludzi jako motyw literacki we współczesnej prozie latynoamerykańskiej}

Celem niniejszego artykułu jest analiza azteckiej praktyki składania ofiar z ludzi, zarówno w jej oryginalnym znaczeniu religijnym i rytualnym, jak i w funkcji motywu literackiego w prozie latynoamerykańskiej XX i XXI wieku. Krwawy rytuał ofiarniczy był nieodłącznym elementem światopoglądu dawnych Azteków oraz spełniał ważną rolę religijną i polityczną. Pozwalał na komunikację ze światem nadprzyrodzonym poprzez wymianę energii życiowej, z czasem przekształcając się również w demonstrację autorytetu państwowego o znaczeniu politycznym. Cztery wybrane do analizy przykłady prozy latynoamerykańskiej pozwalają prześledzić literacką reinterpretację ofiar z ludzi nawiązującą do różnych cech konotacyjnych tego rytuału. Motyw ofiary ludzkiej w prozie współczesnej oddala się od pierwotnego, religijnego znaczenia obrzędu, przeradzając się w symbol przemocy historycznej, lęków egzystencjalnych oraz rzeczywistości pozarozumowej.

Słowa kluczowe: ofiary z ludzi, przemoc, Xipe Totec, Huitzilopochtli, obrzęd aztecki 